\title{
Impacto da pandemia nas atividades dos agricultores familiares da feira municipal de Cascavel -Paraná, Brasil
}

Impact of the pandemic on the activities of family farmers at the municipal fair in Cascavel Paraná, Brazil

Impacto de la pandemia en las actividades de los agricultores familiares en la feria municipal de Cascavel - Paraná, Brasil

\begin{abstract}
Resumo
A agricultura familiar é a principal responsável pela alimentação do País e está ligada diretamente à segurança alimentar e ao desenvolvimento do local onde está inserida. Assim, este trabalho teve como objetivo geral compreender e analisar as dificuldades dos agricultores familiares participantes da feira municipal de Cascavel - PR para venderem seus produtos na pandemia COVID-19. Em relação à metodologia, esta pesquisa caracteriza-se como bibliográfica, exploratória e qualitativa. A coleta de dados ocorreu por meio da aplicação de questionários com os agricultores familiares da feira municipal. Os resultados da pesquisa identificaram que novos canais de divulgação como estratégia para aumentar a visibilidade dos agricultores familiares e as vendas dos produtos são muito importantes, pois na pandemia os agricultores da feira municipal de Cascavel tiveram suas vendas diminuídas em até $70 \%$, em decorrência dos decretos municipais, impedindo a abertura da feira, diminuindo a quantidade de ônibus circulando, o que limita o acesso à feira, principalmente, dos idosos que utilizam esse meio de transporte e por conta do fechamento das escolas, afetando os participantes de programas como o PAA (Programa de Alimentação Escolar) e PNAE (Programa Nacional de Alimentação Escolar). Conclui-se que a pandemia COVID-19 repercutirá de várias formas na agricultura familiar, em relação aos agricultores familiares da feira municipal, a pesquisa revelou que são necessárias estratégias locais para amenizarem os seus efeitos negativos.
\end{abstract}

Palavras-chave: Agricultura familiar; Feiras; Pandemia COVID-19.

\begin{abstract}
Family farming is the main responsible for the country's food supply and is directly linked to food security and the development of the place where it operates. Thus, this work aimed to understand and analyze the difficulties of family farmers participating in the fair. Cascavel - PR to sell their products in the COVID-19 pandemic. Regarding the methodology, this research is characterized as bibliographical, exploratory and qualitative. Data collection occurred through the application of questionnaires with family farmers at the municipal fair. The survey results identified that new channels of dissemination as a strategy to increase the visibility of family farmers and product sales are very important, as in the pandemic, farmers at the Cascavel municipal fair had their sales reduced by up to $70 \%$, due to the municipal decrees, preventing the opening of the fair, reducing the number of buses circulating, which limits access to the fair, especially for the elderly who use this means of transport and because of the closing of schools, affecting participants in programs such as the PAA (School Feeding Program) and PNAE (National School Feeding Program). It is concluded that the COVID-19 pandemic will have repercussions in various ways on family farming, in relation to family farmers at the municipal fair, the research revealed that local strategies are needed to mitigate its negative effects.
\end{abstract}

Keywords: Family farming; Fairs; Pandemic COVID-19.

\section{Resumen}

La agricultura familiar es la principal responsable del abastecimiento alimentario del país y está directamente vinculada a la seguridad alimentaria y al desarrollo del lugar donde opera. Así, este trabajo tuvo como objetivo comprender y analizar las dificultades de los agricultores familiares que participan en la feria. Cascavel - PR para vender sus productos en la pandemia COVID-19. En cuanto a la metodología, esta investigación se caracteriza por ser 
bibliográfica, exploratoria y cualitativa. La recolección de datos se realizó mediante la aplicación de cuestionarios con agricultores familiares en la feria municipal. Los resultados de la encuesta identificaron que los nuevos canales de difusión como estrategia para aumentar la visibilidad de los agricultores familiares y la venta de productos son muy importantes, ya que en la pandemia, los agricultores de la feria municipal de Cascavel vieron reducidas sus ventas hasta en un $70 \%$, debido a la decretos municipales, impidiendo la apertura de la feria, reduciendo el número de buses circulando, lo que limita el acceso a la feria, especialmente para las personas mayores que utilizan este medio de transporte y por el cierre de escuelas, afectando a participantes en programas como el PAA (Programa de Alimentación Escolar) y PNAE (Programa Nacional de Alimentación Escolar). Se concluye que la pandemia COVID19 tendrá repercusiones de diversas formas en la agricultura familiar, en relación a los agricultores familiares en la feria municipal, la investigación reveló que se necesitan estrategias locales para mitigar sus efectos negativos.

Palabras clave: Agricultura familiar; Ferias; Pandemia de COVID-19.

\section{Introdução}

Não há uma unanimidade em relação a definição de agricultura familiar, o que se observa é muita discussão e o que permanece em várias vertentes é a base familiar da unidade de produção, sendo diferenciados pelos estabelecimentos familiares e não familiares (Meliczek, 2003). De acordo Guanziroli e Cardim (2000), até os anos 90, a agricultura familiar possuía carácter de subsistência, consistindo na relação entre produção e consumo de alimentos, posteriormente, foi incorporada a uma complexa estrutura, devido ao aumento da população urbana, adoção de tecnologia e a uma integração entre mercados, transformando o alimento em mercadoria (Paula, 2017). Após a década de 90, ela foi considerada importante para o desenvolvimento do País e teve reconhecimento com a criação de políticas públicas (Esquerdo-Souza \& Bergamasco, 2015), se consagrando com o Programa Nacional de Fortalecimento da Agricultura Familiar (PRONAF) e projeto Fome Zero, passando ser vista como estratégia, gerando emprego e renda (Stofell, 2004, Schneider, 2009, Plansan, 2011 \& Guilhoto et al., 2005).

A agricultura familiar é responsável por $70 \%$ da produção dos alimentos da cesta básica dos brasileiros (Contraf Brasil, 2020)" e segundo o censo agropecuário de 2006, o agricultor familiar condiz a $10 \%$ e $38 \%$ do Produto Interno Bruto (PIB) e do Valor Bruto da Produção Agropecuária, respectivamente (Portal Brasil, 2014). Para o Plansan (2017), a agricultura familiar é a principal responsável pela alimentação no País e está ligada diretamente à segurança alimentar (Fao, 2015) e ao desenvolvimento do local onde está inserida (Alfatin, 2003), o qual está atrelado à melhoria da qualidade de vida das pessoas e essa busca pela melhora na qualidade de vida deve envolver estratégias de desenvolvimento econômico executadas regionalmente ou localmente (Maluf, 2000), gerando renda para os municípios, promovendo o desenvolvimento local (Almeida et al., 2007).

Como foi apresentado, a agricultura familiar tem participação significativa no contexto econômico do País, no entanto, eles enfrentam muitos desafios no dia-a-dia das atividades rurais, como: pouca terra para produção, baixo recurso financeiro, (oriundos de políticas do Governo Federal ou da iniciativa privada), dificuldade de assistência técnica, logística, dificuldades de acesso ao mercado, os quais restringem os pequenos produtores, principalmente em relação à competitividade. Esses desafios somados à pandemia COVID-19 fizeram com que os agricultores familiares tivessem dificuldades na venda dos produtos e impactou diretamente em menores rendas.

Neste âmbito, algumas ações já vinham sendo acionadas pelos agricultores familiares com o propósito de abrir novos canais de comercialização e, consequentemente, melhorar a renda, como investir na diversificando da sua produção, utilizar tecnologias e adotar novas técnicas de manejo visando a sustentabilidade (Basso, Silva \& David, 2019). Dentre os canais de comercialização da agricultura familiar que têm crescido, temos as feiras livres que são espaços de comércio e também de relacionamento entre consumidor e produtor. Esse tipo de comércio se enquadra nos circuitos curtos de comercialização (CCC) e de acordo com Schneider et al. (2016, p. 127) é um canal de comercialização do mercado de proximidade, sejam feiras livres/locais, agroecológicas ou regionais, elas facilitam acesso aos produtos agrícolas e artesanais (Mds, 2018). 
Buainain e Batalha (2007) afirmam que os circuitos curtos de comercialização podem avivar a relação entre campo e cidade e assim, contribuírem para a criação de novos padrões de consumo, propiciando uma maior autonomia dos agricultores familiares, estimulando a identidade de produtos locais, gerando vantagens econômicas, ambientais e socioculturais e ainda, revalorizando os espaços rurais. Para Scarabelot \& Schneider (2012), esse tipo de comercialização ajuda na resolução de dois desafios enfrentados pelos agricultores rurais, o custo de produção, com a adoção de tecnologias, custos com logística, dependência de insumos externos, entre outros e a produção de alimentos saudáveis e seguros.

De acordo com a Organización Panamericana de la Salud, esta forma de comércio, promove o acesso à produtos como frutas e verduras que nutrem adequadamente, "o desenvolvimento de CCC oferecem diversos alimentos seguros e saudáveis e permitem melhorar o acesso a uma dieta saudável para as populações com graus mais elevados de vulnerabilidade" (Ops, 2020, p. 112), esses alimentos também são essenciais para uma alimentação saudável e segura para aumentar a imunidade e terem os sintomas menos graves da COVID-19 e para pessoas com sobrepeso e obesidade que precisam ter uma alimentação balanceada, uma vez que, essas doenças são um sério fator de risco, no caso de uma infecção pelo vírus, pois, é fato que a obesidade está associada ao risco de sofrer efeitos piores caso seja contaminado (Ops, 2020).

Segundo Schneider et al. (2020, p. 11) "equivocadamente, no início da pandemia diversos mercados e feiras locais foram suspensos ou tiveram seu funcionamento restringido por autoridade locais e sanitárias. Esses espaços, têm como principal oferta alimentos frescos, sazonais e, portanto, com maior qualidade nutricional, importantes ao combate do novo coronavírus". Ainda de acordo com o mesmo autor, a quantidade de consumidores não acompanhou a reabertura das feiras, ora por estarem evitando deslocar-se para esses mercados, levando muitos agricultores a diminuírem a produção.

Um estudo realizado em Corumbá, no Mato Grosso do Sul, afirma que “ a suspensão das feiras livres e diversas outras medidas de restrições para diminuir a circulação de pessoas sem dúvida é essencial para evitar e/ou diminuir o contágio da doença, mas essas restrições afetaram a economia e as finanças dos feirantes, uma vez que, a feira é o ganha pão deles" (Freitas, 2020, p. 23 ). Outro estudo realizado no Estado de Sergipe revela que os agricultores familiares da feira do município de Itabaiana tiveram queda nas vendas e como consequência, diminuíram a produção por causa da pandemia do coronavírus (Senar, 2020).

Nesse contexto, este artigo tem como problema de pesquisa, identificar o impacto da pandemia nas atividades dos agricultores familiares da feira municipal de Cascavel - Paraná, Brasil. Para responder ao problema têm-se como objetivo geral, compreender e analisar as dificuldades dos agricultores familiares participantes da feira municipal de Cascavel - PR para venderem seus produtos na pandemia COVID-19.

Esta pesquisa está estruturada em três capítulos. Além deste capítulo que apresenta a introdução, no segundo capítulo está descrita a metodologia, na sequência estão dispostos os resultados e discussões parciais e por fim, serão apresentadas as conclusões, bem como as referências bibliográficas da pesquisa.

\section{Metodologia}

Esta pesquisa caracteriza-se como bibliográfica e exploratória, em relação aos seus resultados se trata de um estudo qualitativo, pois visa apresentar os impactos da pandemia, compreendendo e analisando as dificuldades dos agricultores familiares participantes da feira municipal de Cascavel - PR para venderem seus produtos na pandemia COVID-19.

De acordo com Gil (2010), a pesquisa bibliográfica é realizada por meio de material já publicado, por exemplo, livros, sites, artigos de periódicos e com material disponibilizado na internet, enquanto a pesquisa exploratória, visa proporcionar uma maior familiaridade com o problema, por meio do levantamento bibliográfico. Essa junção de pesquisas tem por objetivo descrever completamente determinado fenômeno (Marconi \& Lakatos, 2004). 
Este estudo possui natureza quantitativa em relação aos resultados que se pretende apresentar, pois trata-se de um estudo para compreender e analisar as dificuldades que os agricultores familiares da feira municipal de Cascavel - PR estão enfrentando neste momento de pandemia para venderem seus produtos, visando que ações possam ser elaboradas e executadas a partir dos resultados, a fim de fortalecer e desenvolver a agricultura familiar no município e, ainda poderá melhorar os índices de segurança alimentar e nutricional do município de Cascavel. A pesquisa qualitativa possibilita uma melhor visão e compreensão da complexidade e do contexto do problema a ser estudado (Malhotra, 2001).

Para responder ao problema de pesquisa deste trabalho: impacto da pandemia nas atividades dos agricultores familiares da feira municipal de Cascavel - Paraná, Brasil. E para atender ao objetivo geral: Compreender e analisar as dificuldades dos agricultores familiares participantes da feira municipal de Cascavel - PR para venderem seus produtos na pandemia COVID-19, foi realizado um levantamento de dados por meio de entrevistas, com as quais obtêm-se informações sobre um problema se deseja conhecer, analisando as respostas relatadas (Gil, 2010), e posteriormente foi aplicado um questionário para os agricultores familiares participantes da feira local do município de Cascavel - PR, para identificarmos quais as dificuldades enfrentadas por eles para a venda dos produtos na pandemia.

As entrevistas realizadas foram classificadas como semiestruturadas, esse tipo de entrevista dá liberdade ao entrevistador de direcionar a conversação à situação adequada, conseguindo explorar mais amplamente alguma questão e podese fazer uso de um roteiro para tal (Marconi \& Lakatos, 2004). As entrevistas foram realizadas com a Teresinha Barron, Extensionista do município de Cascavel, a Karolline Marques da Silva, Coordenadora estadual de agroindústria, ambas no dia 18 de março de 2021, via ferramenta Google Meet e aplicativo WhatsApp, respectivamente, com a Margarete Tonin, Coordenadora do PMAE do município de Cascavel, Raquel Marca Coordenadora do PAA do município de Cascavel, ambas no dia 03 de novembro de 2020, via contato telefônico.

Os questionários foram compostos por 11 questões, sendo 03 abertas e 07 de múltipla escolha. Em relação aos respondentes, participaram da pesquisa de 39 dos 75 agricultores familiares da feira municipal atualmente, responderam ao questionário somente os agricultores familiares que comercializam produtos oriundos da agricultura familiar, assim, os vendedores de lanches, espetinhos, bombons, artesanatos e vendedores de produtos obtidos de terceiros não foram questionados por conta do viés da pesquisa e no momento 10 agricultores familiares idosos também não foram questionados por estarem afastados por conta de pandemia. Os questionários foram feitos na ferramenta Google Forms, por meio dela foram extraídos alguns gráficos e outros gráficos foram refeitos no Microsoft Excel para uma melhor visualização dos dados.

\subsection{Critério de seleção e local da pesquisa}

A seleção das pessoas a serem entrevistas e para responderem ao questionário foi realizada utilizando a técnica Delphi, na qual especialistas são selecionados conforme o seu grau de experiência, envolvimento e conhecimento no assunto, podendo contribuir de maneira satisfatória com a pesquisa. A técnica permite que as conversas entres os especialistas seja organizada, a fim de obter um consenso geral (Crespo, 2007). Assim, opta-se pela escolha dos agricultores familiares integrantes da feira municipal. A partir disso, foi possível identificar as dificuldades enfrentadas por esses agricultores familiares, principalmente na pandemia, quais são os canais de comercialização utilizados por eles e quais estratégias estão sendo utilizadas para a venda dos produtos.

Em relação a feira, ela acontece semanalmente no município de Cascavel - PR em dois lugares, um deles é dentro do estacionamento do Teatro Municipal Cultural Gilberto Mayer (às terças e quintas-feiras, das $12 \mathrm{~h}$ às $19 \mathrm{~h}$, dependendo do horário do toque de recolher) e o outro lugar é em frente a prefeitura municipal de Cascavel (aos sábados e domingos, das 6h às $12 \mathrm{~h})$. 
Foi realizada a validação de questionários com a participação de 10 agricultores familiares na feira do estacionamento do teatro, no dia 06 de maio de 2021, para verificar a necessidade de realizar mudanças no questionário, o que não foi necessário, e mais duas aplicações aconteceram nos dias 20 e 22 de maio de 2021, na feira do estacionamento do Teatro e em frente à prefeitura, respectivamente, no dia 20, 18 agricultores familiares foram questionados e no dia 22, totalizaram 11 questionados. A aplicação dos questionários foi realizada mediante autorização do presidente da feira, Sr. Jeferson Bonatto, por meio de um termo assinado por ele.

\section{Resultados e Discussão}

Para atender ao problema da pesquisa e ao objetivo geral foram estudadas as dificuldades dos agricultores familiares participantes da feira municipal de Cascavel - PR para venderem seus produtos na pandemia COVID-19, as quais serão detalhadas a seguir.

As Figuras 1 a 4 abaixo apresentam as informações obtidas por meio das respostas do questionário aplicado aos 39 agricultores familiares participantes da feira local do município de Cascavel, nelas podemos observar, além das dificuldades, os produtos vendidos, onde as propriedades estão localizadas, os canais de comercialização dos produtos e a divisão dos empreendimentos da feira municipal.

O primeiro dado da Figura 1, apresenta o endereço das propriedades, ela permite observarmos que a maior parte dos produtos vendidos são produzidos no distrito de São Salvador (11), assim a distância, ou seja, a logística, principalmente, por conta do aumento do combustível é um fator que foi citado por alguns agricultores com um fator de dificuldade na pandemia, impactando em menor renda para esses agricultores.

Figura 1: Endereço das propriedades.

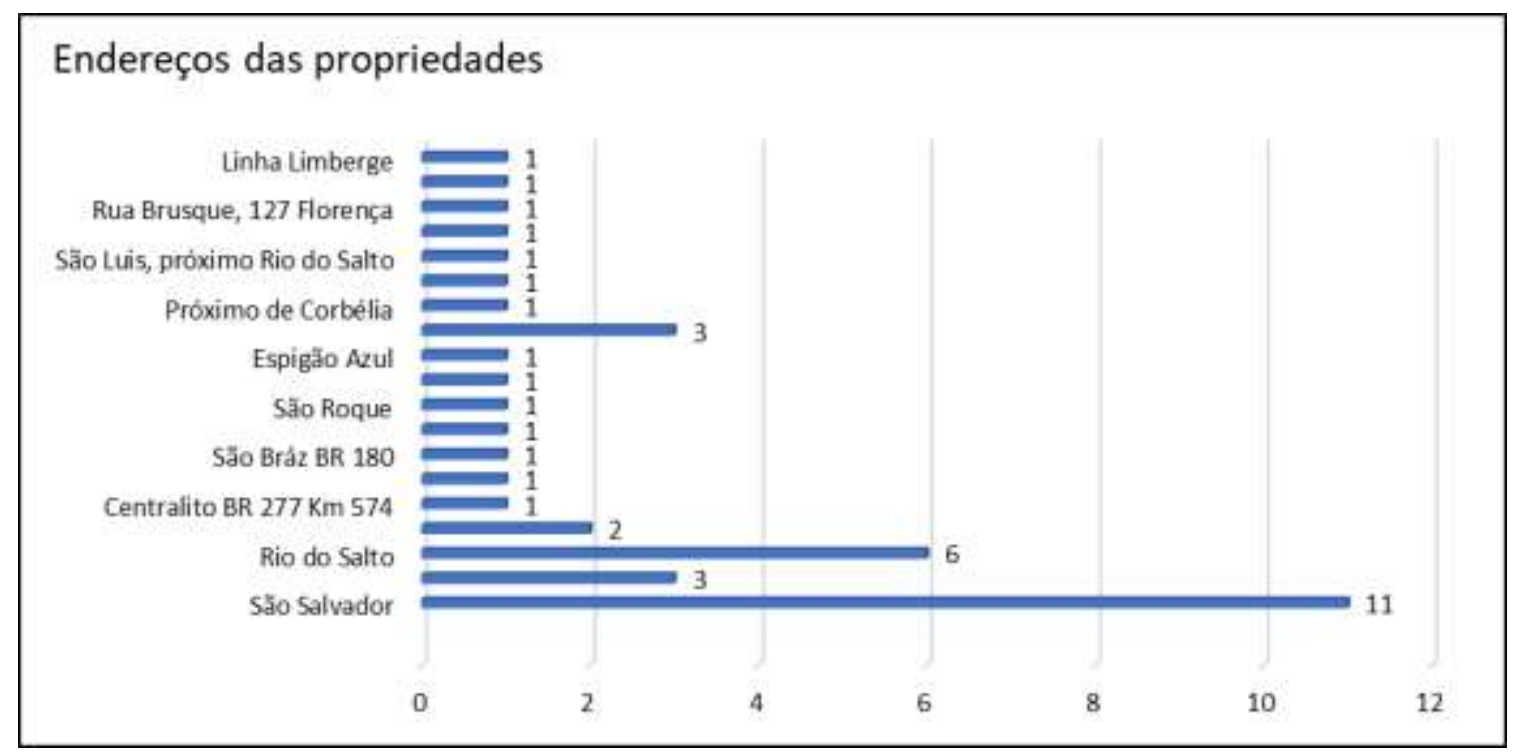

Fonte: Autores, com o auxílio do Microsoft Excel (2021).

Neste âmbito, uma ajuda de custo por parte da gestão municipal e a redução ou abono do preço cobrado pelo pedágio, no caso de agricultores que passam por ele para levarem a produção até a feira, é uma boa estratégia a ser elaborada pela gestão municipal, para que eles não tenham seu lucro reduzido e também, para que o repasse deste custo ao consumidor seja menor ou não aconteça. 
Em relação aos produtos produzidos pelos agricultores familiares, a maioria produz legumes (22) e verduras (16), o que corresponde, respectivamente a $56,4 \%$ e $41 \%$, as frutas, doces ou compotas aparecem em terceiro lugar, com 15 produtores, ou seja, 38,5\%, na sequência se posiciona o produto leite e derivados com 9 agricultores familiares (20,5\%), mel e derivados são produzidos por 6 agricultores $(15,4 \%)$, panificados e bolachas por 5 produtores $(12,8 \%)$, os produtos carne e derivados e tempero verde, ambos são produzidos por 4 dos agricultores questionados, o que representa 10,3\%, conforme mostra a Figura 2 abaixo.

Figura 2: Produtos produzidos nas propriedades.

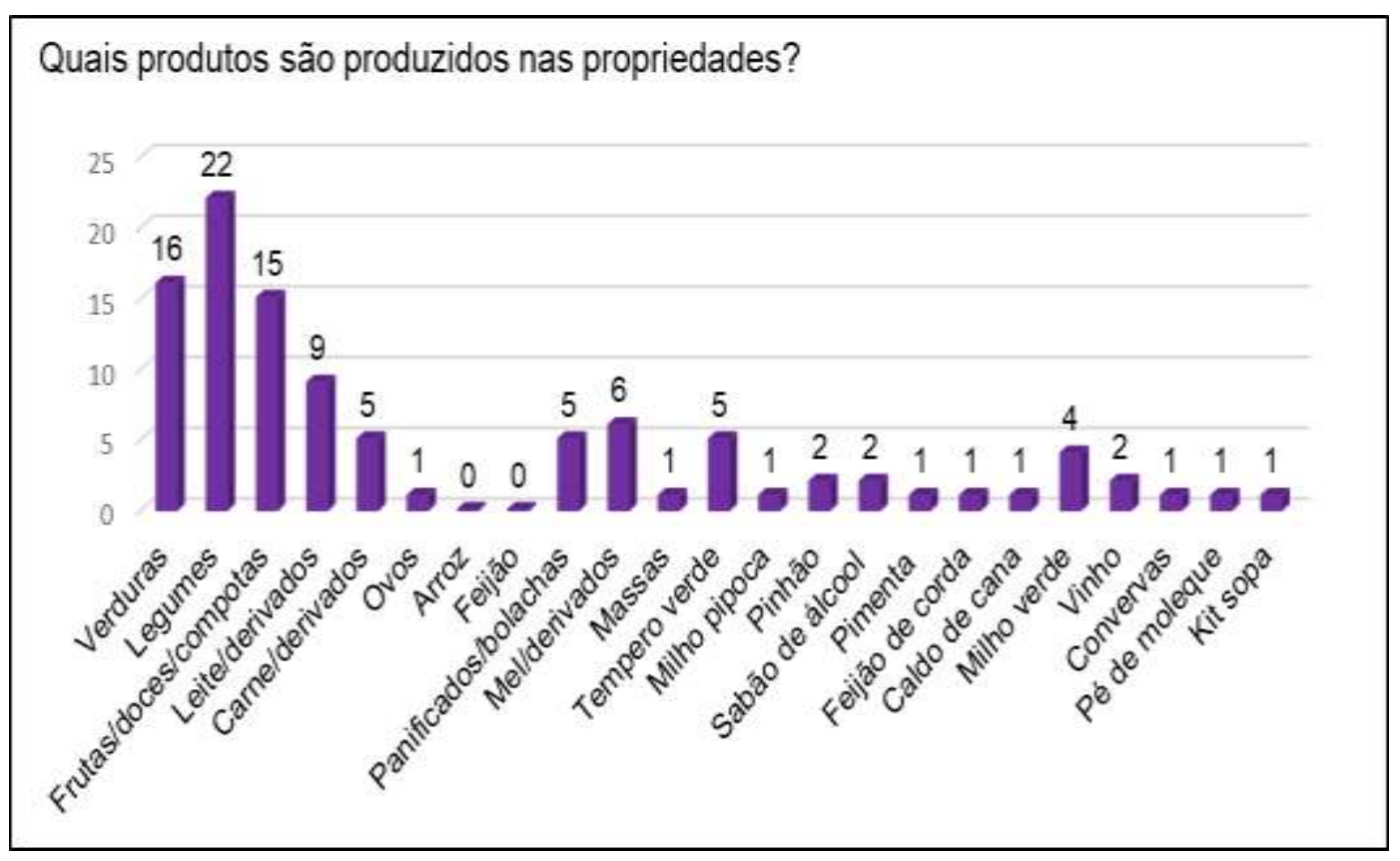

Fonte: Autores, com o auxílio do Microsoft Excel (2021).

Os produtos menos citados foram os ovos, massas, milho pipoca, pinhão, sabão de álcool, pimenta, feijão de corda, caldo de cana, vinho, conversas, pé de moleque e o kit sopa, apenas um agricultor familiar produzem cada produto e os comercializam na feira do produtor do município. Eles relataram que o pinhão, o kit sopa e o vinho por exemplo, são vendidos mais no inverno, principalmente, o pinhão por ser um fruto desta época do ano, já o caldo de cana é mais consumido no verão pelos clientes da feira.

Neste sentido, vários agricultores familiares da feira municipal afirmaram que o aumento no custo da matéria-prima, como mudas, sementes, ração o gado, farinha de trigo, energia, embalagens, fez com que a produção fosse reduzida e os investimentos na produção fossem suspensos, alguns agricultores comentaram que tem receio de investirem e não ter para quem vender a produção, devido ao movimento estar fraco na pandemia.

Em relação aos produtos mais produzidos, nota-se que a produção de verduras e legumes sofreram impacto direto com o aumento do custo das mudas e sementes, sendo uma oportunidade para os agricultores aprenderem novas técnicas de plantio, como por exemplo, a extração das sementes. Embora a obtenção de sementes de algumas hortaliças (espécies híbridas) dependa de tecnologia geralmente não acessível, a produção de sementes de variedades locais, de material genético de domínio público ou polinização aberta é uma possibilidade para a redução de custos de produção.

A Figura 3 logo abaixo, apresenta por quais canais os agricultores familiares vendem os seus produtos, os mais citados foram, em primeiro lugar, a própria feira, em segundo lugar ficou o PAA com 17 agricultores $(43,6 \%)$, em terceiro 
lugar ficaram posicionados o PNAE e a venda na propriedade com 8 agricultores (20,5\%), 5 deles responderam venderem também para restaurantes $(12,8 \%)$.

Dentre os menos citados temos, vendas porta a porta, mercados locais, comércio em geral, exército, entregas delivery, refeitórios de empresas, venda de marmitas, panificadoras, igrejas, PLC - Programa do Leite da Criança e eventos, esse último, por conta dos decretos, não permitindo aglomerações de pessoas em decorrência da pandemia, eles não têm ocorrido e assim, os agricultores não tem vendido para essa atividade.

Figura 3: Canais de comercialização dos produtos.

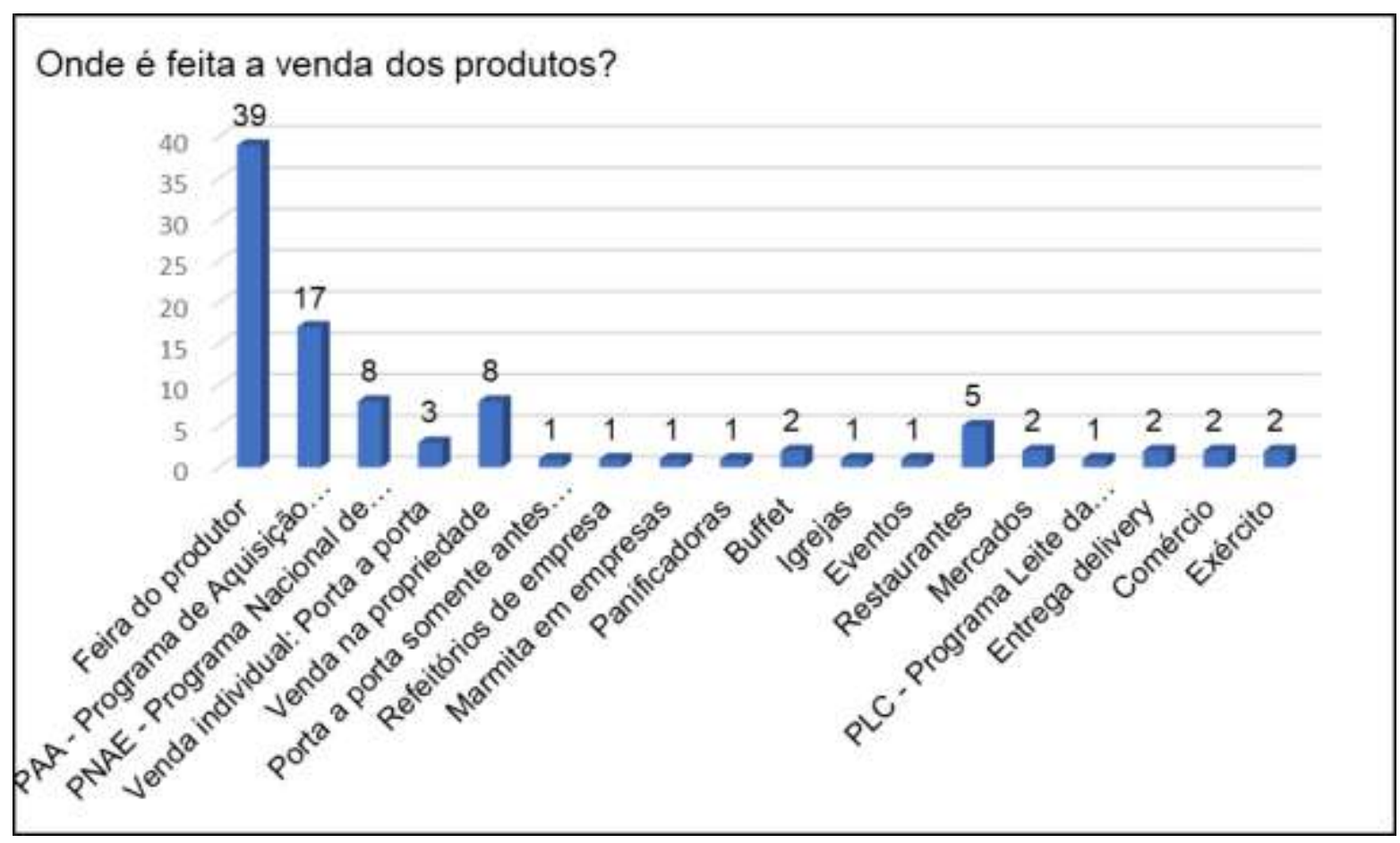

Fonte: Autores, com o auxílio do Microsoft Excel (2021).

Em relação a essas respostas, fica bem claro que novas oportunidades podem ser criadas para abertura de novos canais de comercialização e que os canais de comercialização dos produtos que atualmente são pouco explorados, os quais foram menos citados pelos feirantes, como os mercados locais e entregas delivery, podem ser fomentados para auxiliar no aumento das vendas não somente na pandemia, mas no pós pandemia.

De acordo com as entrevistas concedidas pela Raquel Marca, coordenadora do Programa Aquisição de Alimentos (PAA) e pela Margarete Tonin, coordenadora do Programa Municipal de Alimentação Escolar (PMAE) no município de Cascavel - PR, a venda para os programas PAA, Programa Nacional de Alimentação Escolar (PNAE) e PMAE fortalecem a agricultura familiar e também a segurança alimentar e nutricional do município (Marca \& Tonin, 2020). Ainda segundo a Raquel Marca, em 2021, a compra dos produtos dos agricultores familiares acontecerá por meio do PAA, via chamada pública, a Cooperativa de orgânicos do município Cores da Terra em parceria com a Cooperativa Apropal do município de Palmas - PR vai atender a demanda de produtos orgânicos para a merenda municipal (Marca, 2021).

É importante frisar que apenas um dos dois agricultores produtores de orgânicos da feira municipal entregam para tais mercados institucionais, tal fato demonstra que há pouca relação com a segurança alimentar, no sentido de alimentação segura e saudável, o que pode ser incentivado estrategicamente pela gestão da feira e pela gestão municipal.

Para a diretora regional do Unicef para a América Latina e o Caribe, Jean Gough, para que as crianças cresçam saudáveis e não corram risco de desnutrição em tempos de pandemia, "é urgente garantir a disponibilidade de alimentos 
saudáveis (Fao, 2020)". Esses alimentos também são essenciais para os adultos que precisam de uma alimentação saudável e segura para aumentar a imunidade e terem os sintomas menos graves da COVID-19 e para pessoas com sobrepeso e obesidade que precisam ter uma alimentação balanceada, uma vez que, essas doenças são um sério fator de risco, no caso de uma infecção pela COVID-19, pois, é fato que a obesidade está associada ao risco de sofrer efeitos piores caso seja contaminado (Ops, 2020).

A coordenadora do PMAE compra os produtos dos agricultores familiares para preparo da merenda das escolas municipais, essa compra é realizada por meio de recursos livres provenientes da prefeitura do municipal de Cascavel. Segundo ela, em 2019 foram utilizados em torno de $\mathrm{R} \$ 11$ mil reais para essas compras e em torno de 3 mil reais foram utilizados do PNAE Federal para compras para a merenda das escolas estaduais. Ela complementa que, o uso do PNAE Federal em 2019 foi de $67 \%$ e no ano de 2020 foi de em média 40\%. No final do ano 2020 (novembro/dezembro) todos os produtos para a produção da merenda dos alunos vinculados ao bolsa família estavam previstos para serem comprados com recursos livres, já para os alunos da rede estadual a previsão era o uso de recursos federais do PAA. O cadastro no bolsa família (CADÚnico) para acesso aos kits escolares teve início em maio de 2020, mas as entregas aconteceram em a partir de agosto de 2020 (Tonin, 2020). Essa questão evidencia o fomento à agricultura familiar no município de Cascavel tão importante para o desenvolvimento e fortalecimento do setor e também para diminuir os índices de insegurança alimentar e nutricional.

De acordo com a Fao (2015), quando a agricultura familiar é trabalhada em conjunto com outras políticas, ela pode contribuir com o desenvolvimento local, avivando as economias locais e ajuda diminuir os índices de insegurança alimentar, uma vez que, para Alfatin (2003), ela está intimamente ligada à segurança alimentar. Percebe-se por meio das entrevistas, que esse trabalho conjunto é o que está sendo realizado no município.

Para Ploeg (2011), os mercados institucionais são essenciais para a redução da pobreza e para a inclusão dos agricultores familiares no mercado e apenas 1 agricultor citou como dificuldade para se inserir neste mercado, a quantidade de papéis e o pouco tempo para envio para participação dos editais e 5 deles disseram que o fechamento das escolas teve impacto na redução das vendas e, consequentemente, da renda familiar.

Com o resultado desta pergunta, pode-se afirmar que o impacto seria menor com a diversificação de meios de comercialização, o que deve ser estimulado pela gestão da feira e gestão municipal. A extensionista municipal, Teresina Barron, ligada diretamente aos agricultores familiares da feira municipal, relatou em entrevista, que os agricultores que vendem para os mercados institucionais não sentiram tanto as dificuldades da pandemia, o que foi confirmado pela também entrevistada Karolline Marques da Silva, coordenadora estadual de agroindústria "O mercado institucional é forte em Cascavel, então foram poucas as dificuldades", Barron explica que tal fato é devido eles venderem para outros locais como o exército, quartel e hospital universitário, por exemplo, mas, no entanto, os resultados da pesquisa mostram que apenas dois agricultores questionados entregam para o exército e nenhum deles citaram o quartel ou o hospital.

Os produtores de mercados institucionais sofreram pouco com os cortes institucionais por conta dos programas municipais, parcerias para vendas inclusive para o quartel e para o $\mathrm{HU}$, no entanto, com a pandemia as escolas fecharam e esses agricultores estão entregando os kits.

Os produtores das feiras estão sofrendo bastante com a pandemia, além de terem trocado várias vezes de lugar, foram da praça Wilson Jofre que está sendo revitalizada para o antigo terminal Leste e agora estão na rua, na frente do centro cultural Gilberto Mayer (teatro) (Barron, 2021).

A coordenadora estadual de agroindústria, relatou que no cenário estadual uma das dificuldades foi a adaptação cardápio feita pelos nutricionistas para atender o plano de segurança alimentar e nutricional, por conta da necessidade de uma dieta balanceada, segundo ela, os panificados por exemplo são comprados em quantidades menores.

Ela completa que, quando perceberam os cortes nas compras de alguns produtos e maior incerteza perante maior concorrência (cooperativas) - pois muitos agricultores se unem em cooperativas para participarem de editais - para que os 
agricultores sentissem menos o impacto desses fatores, eles incentivaram os agricultores a não dependerem somente deste mercado, alguns deles já tinham agroindústria e aqueles que já tinham um perfil empreendedor, principalmente, os que tinham o negócio como fonte de renda principal, passaram a produzir produtos minimamente processados, como a mandioca, que era lavada, descascada e rotulada para entregarem para os mercados institucionais e o incentivo foi para venderem para os mercados locais (mercadinhos, padarias...). Ainda segundo a coordenadora, os agricultores que tinham uma idade avançada, que produziam em menor escala e não dependiam da agroindústria, ou seja, o negócio era para uma renda complementar, foram os que mais sentiram por conta dos fatores citados anteriormente (Silva, 2021). No âmbito do município de Cascavel, o Quadro 1 abaixo apresenta algumas dificuldades enfrentadas pelos agricultores familiares da feira municipal durante a pandemia COVID-19.

Quadro 1: Descrição das dificuldades enfrentadas pelos agricultores familiares da feira municipal de Cascavel-PR.

\begin{tabular}{|l|r|}
\hline Poucas chamadas públicas & 0 \\
\hline Dificuldade para participar dos editais, como: muita papelada, pouco tempo para entregar a papelada. & 1 \\
\hline Fechamento das escolas & 0 \\
\hline O meu produto não é comprado para os kits escolares. & 25 \\
\hline Restrição de horários para abertura do comércio & 13 \\
\hline Restrição dos horários de circulação dos ônibus (no caso dos feirantes). & 25 \\
\hline Local de entrega ou venda dos produtos & 3 \\
\hline Custo da farinha de trigo & 5 \\
\hline Custo do Combustivel & 3 \\
\hline Custo da ração & 9 \\
\hline Diminuíram as vendas & 2 \\
\hline Diminuíram as vendas (em torno de 70\%) & 1 \\
\hline Decretos & 5 \\
\hline Custo da matéria-prima & 1 \\
\hline Custo dos copos & 1 \\
\hline Custos das embalagens & 2 \\
\hline Local afastado do centro e longe das paradas de ônibus para Sta Teresa e Corbélia & 1 \\
\hline Custo das mudas & 2 \\
\hline Custo da energia & 1 \\
\hline Falta de vagas de estacionamento & 1 \\
\hline Pouco movimento e alguns dias não tem feira por conta dos decretos & 1 \\
\hline Pouco movimento e alguns dias não tem feira por conta dos decretos & 1 \\
\hline Só teve dificuldades de vendas na primeira semana da pandemia & 1 \\
\hline Antiga gestão da feira & 1 \\
\hline Não consegue aumentar a produção, pois não tem para quem vender & 1 \\
\hline Custo das sementes & 1 \\
\hline Custo com o pedágio & 1 \\
\hline Falta de politicas públicas municipais & 1 \\
\hline Falta de ajuda da prefeitura para divulgar a mudança de local & 2 \\
\hline Dificuldade de adaptação das pessoas em relaça ao local e uso de máscaras, não tocar nos produtos & 1 \\
\hline Crise financeira da população & \\
\hline
\end{tabular}

Fonte: Autores, com o auxílio do Microsoft Excel (2021).

As dificuldades mais citadas por eles são: restrição de horários para abertura do comércio por conta dos decretos e a mudança do local de entrega ou venda, as quais ambas contemplaram 25 agricultores (64,1\%), a restrição dos horários de circulação dos ônibus foi citada por 13 agricultores (33, 3\%), 9 agricultores relataram que as vendas diminuíram significativamente $(23,07 \%), 2$ deles disseram que diminuíram em torno de $70 \%$. 
Dentre as dificuldades menos citadas, temos em quinto lugar, o fechamento das escolas, bem como o custo do combustível e o custo da matéria-prima, contemplando 5 respostas, o que corresponde a 12,8\% dos agricultores familiares questionados, seguidos por 3 agricultores que produzem panificados e leite/derivados (7,69\%) os quais citaram o custo da farinha de trigo e o custo da ração para alimentação do gado como fatores de dificuldades, respectivamente, por fim outras dificuldades foram relatadas por 1 agricultor, como a crise da população, pouco movimento na feira, adaptação dos clientes, local da feira afastado do centro com poucas vagas de estacionamento e problemas com a antiga gestão feira.

Para a extensionista municipal Teresinha Barron, os agricultores familiares, principalmente, os participantes da feira municipal, tiveram redução da renda devido aos decretos municipais, os quais impedem a abertura da feira, reduzem o tempo de abertura, por conta do toque de recolher e também restringem a quantidade de ônibus circulando, limitando o uso do transporte coletivo, e assim consequentemente, limita o acesso dos consumidores à feira, Barron cita o exemplo dos idosos que utilizam esse meio de transporte para irem até a feira (Barron, 2021), o que foi confirmado por parte dos agricultores familiares questionados.

Como pode ser observado, a suspensão e, posteriormente, a redução do tempo de abertura da feira, para diminuir a circulação de pessoas, a fim de evitar o contágio pelo coronavírus impactaram em redução da renda dos feirantes do município, neste viés cabe a aproximação dos órgãos municipais e das universidades para encontrarem uma nova estratégia para comercialização dos produtos, permitindo o escoamento da produção e garantindo a renda familiar desses agricultores.

Em relação a mudança do local de entrega ou venda, apesar de não ter relação direta com a pandemia, os agricultores da feira e a extensionista municipal disseram que foi algo que aconteceu durante a pandemia e intensificou a queda nas vendas, segundo eles, devido ao local ser afastado do centro e, principalmente, por conta de os consumidores terem dificuldades de encontrarem o novo local da feira, o qual mudou duas vezes neste período e teve pouca divulgação segundo os agricultores questionados. Entende-se por essa resposta, que é um problema agravado pela pandemia, no entanto, é temporário, pois após a reforma do local antigo da feira ela voltará funcionar nele.

Alguns agricultores relataram, dentre às dificuldades, a ausência de políticas públicas municipais e a pouca assistência por parte da prefeitura municipal, a qual tem condições de ajudá-los mais, principalmente, em relação à mudança de local da feira, por conta da reforma no local antigo. Perante essa resposta pode-se observar a necessidade de políticas públicas voltadas aos agricultores familiares e principalmente, facilidade no acesso a elas, e também é preciso apoio dos órgãos municipais para o desenvolvimento da feira local.

Ainda neste contexto, a divulgação é uma oportunidade que deve ser explorada tanto pelos agricultores familiares de forma individual ou coletivamente, com o apoio da gestão da feira e também da gestão municipal, atualmente a feira local de Cascavel possui uma página coletiva na rede social Facebook, a qual é gerida pela gestão municipal, no entanto, nela a divulgação não foi suficiente para os consumidores encontrarem o novo local da feira. Tal fato também limita o fomento aos circuitos curtos. Para Leite e Teles (2020), esse tipo de auxílio por parte da prefeitura é imprescindível, ele contribui para demonstrar os benefícios que ela traz à cidade, dando maior visibilidade às feiras e aumento de consumidores, essencial diante da diminuição das vendas que chegam a 70\%, de acordo com alguns agricultores da feira.

Dentre as dificuldades mais citadas, destaca-se a queda significativa nas vendas. Essa constatação é preocupante, pois para Reis (2018, p. 31), esse setor é "participante do processo de desenvolvimento das regiões onde está inserido". Assim, a importância dos agricultores familiares tem sido enfatizada, devido aos seus produtos serem destinados a venda direta a consumidores em vários mercados, gerando renda e fomentando o desenvolvimento local (Almeida et al., 2007).

Essa redução das vendas, segundo Schneider (2020), ocorre devido a quantidade de consumidores não ter acompanhado a reabertura das feiras, ora por estarem evitando deslocar-se para esses mercados, levando muitos agricultores a diminuírem a produção e a usarem outras formas de comercialização e divulgação, por meio de plataformas digitais e do uso 
de redes sociais, aumentando significativamente as compras virtuais. Neste sentido, alguns agricultores questionados na pesquisa, disseram que os clientes ainda têm medo e não se adaptaram a dinâmica da feira na pandemia, como por exemplo, a obrigatoriedade do uso de máscaras e a não poderem tocar nos produtos, um dos agricultores cita ainda que o local da feira é afastado do centro da cidade e há poucas vagas de estacionamento para os clientes. Tais fatos, segundo eles, têm diminuído o movimento na feira.

Em relação a esse cenário, o recém eleito presidente da feira Sr. Jeferson Bonatto disse que pretende firmar parcerias com as universidades locais para ajudá-los, principalmente, num primeiro momento, a entender qual o perfil dos clientes da feira para assim, adotar uma estratégia para atingi-los, a fim de aumentar o movimento e, consequentemente, as vendas. Em relação isso, pode-se enfatizar que o gestor da feira não saber dizer qual o perfil dos clientes que passam pela feira é um problema que precisa ser solucionado, evidenciando que as parcerias que estão sendo pensadas por ele serão essenciais para ajudar na criação de ações para que o movimento aumente, sendo importante que as universidades locais estejam disponíveis para auxiliá-lo com pesquisas com esse foco.

Parte dos agricultores familiares da feira (12,8\%), citaram dentre as dificuldades enfrentadas por eles, o alto custo da matéria-prima, como por exemplo. o custo das mudas, das sementes, da ração para alimentação do gado e da farinha de trigo. Os agricultores ainda relataram que não conseguiram repassar esse aumento para o consumidor, eles têm receio de venderem menos se aumentarem os preços dos produtos e justificam que não o fazem devido à crise financeira da população, dificuldade também citada pelos questionados, o que para eles, fez com que a produção fosse reduzida e os investimentos na produção fossem suspensos.

Nota-se por essas respostas que o aumento dos custos na pandemia impactou negativamente na produção e no investimento na produção, havendo a necessidade de criar novas estratégias para produção com menores custos, isso é possível com a interação de órgãos municipais como o Instituto de Desenvolvimento Rural do Paraná - IAPAR-EMATER, promovendo cursos para que os agricultores se aperfeiçoem e se sintam amparados, principalmente, neste momento de pandemia.

Tal momento também é oportuno para investir em novas tecnologias, as quais podem reduzir o custo de produção, e se inserir em um novo mercado, o mercado digital. A Embrapa (2020), afirma que a facilidade de comunicação e de acesso à informação, proporcionada pela internet, são a porta de entrada hoje para introduzir o agricultor nessas novas tecnologias e aplicações capazes de ampliar o acesso a mercados, reduzir custos ou ainda agregar valor à produção.

Dentre as estratégias utilizadas pelos agricultores familiares do município de Cascavel - PR para aumentarem a renda está a consolidação de agroindústrias e a agregação de valor. Com a aplicação dos questionários foram identificadas 10 agroindústrias na feira municipal, contemplando 10\% dos empreendimentos, o que pode ser observado no gráfico da Figura 4 abaixo. Os segmentos são doces, salames e queijos. 
Figura 4: Tipos de empreendimentos rurais.

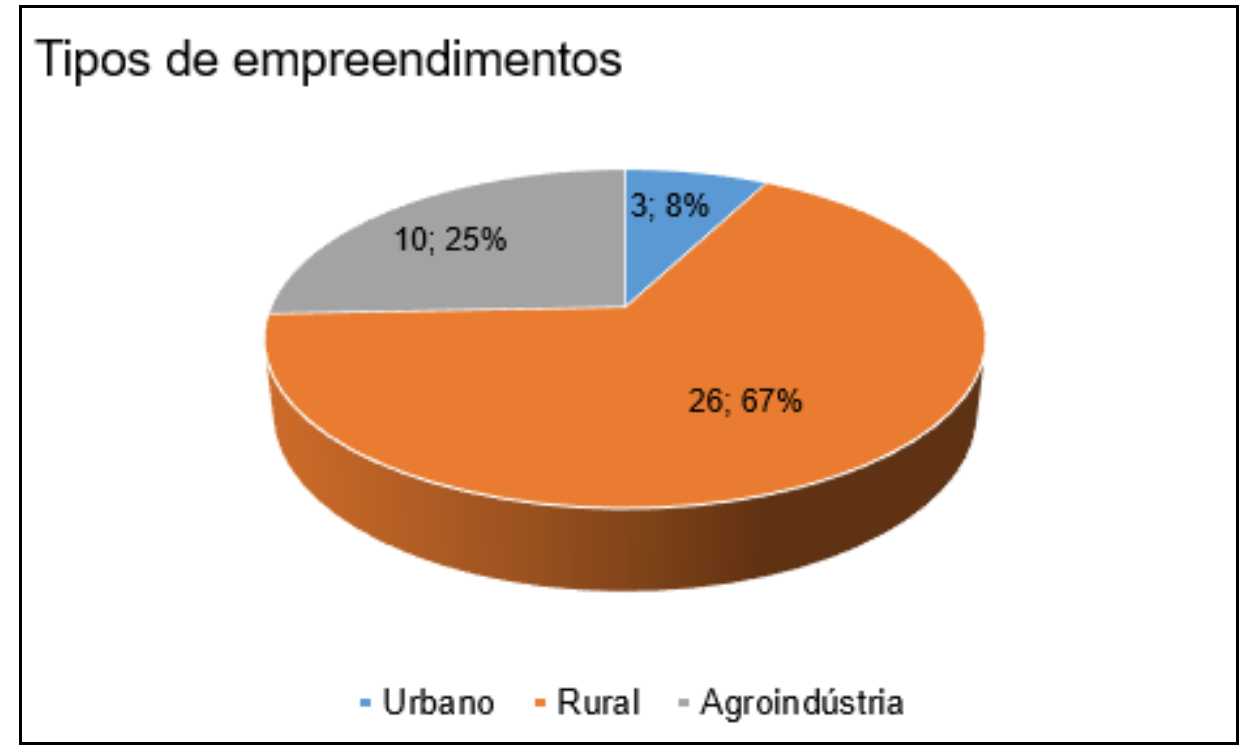

Fonte: Autores, com o auxílio do Microsoft Excel (2021).

Os agricultores familiares veem na agroindústria uma oportunidade para diversificação da produção, venda do excedente e, consequentemente, terem mais uma fonte de renda na propriedade, assim, o processo de agregar valor aos produtos é fundamental para que o resultado esperado por eles seja alcançado. Segundo Maluf (2004) a criação de novos canais de comercialização está associada à valorização de produtos com diferenciados atributos de qualidade. Para Reis (2018, p. 31), a agricultura familiar ganha representatividade quando tem uma propriedade diversificada, que possa lhe garantir a participação em feiras do produtor e ainda transformar a matéria prima em empreendimentos agroindustriais.

A agregação de valor contribui para a incorporação em novos mercados, ela também tende a evitar o êxodo rural com a promoção do desenvolvimento rural e local, uma vez que, gera mais renda e proporciona uma melhor qualidade de vida ao agricultor, é o que afirma o Sebrae (2012), para esse órgão, a agregação de valor possibilita a inserção em novos mercados com um preço mais competitivo, proporcionando maior renda ao produtor e consequentemente, melhor qualidade de vida, além de inibir o êxodo rural, promovendo o desenvolvimento rural e o desenvolvimento local.

Nota-se que com essa questão que a agregação de valor pode auxiliar na diversificação de canais de comercialização, tão importante para os feirantes do município conseguirem escoarem a produção e voltarem fazer investimentos, os quais estão suspensos no momento, também é uma oportunidade para atraírem mais clientes e usarem novos canais de divulgação por meios digitais com a adoção de tecnologia.

Sob a ótica da segurança alimentar e nutricional no município, a partir do levantamento e análise dos dados, também foi possível observar que há pouca relação com a segurança alimentar e nutricional, no sentido de alimentação segura e saudável. Os resultados revelam que apenas um dos dois agricultores familiares produtores de orgânicos da feira municipal, entregam para os mercados institucionais do município de Cascavel, o que pode ser incentivado e melhor explorado tanto pela gestão da feira quanto pela gestão municipal, pois é uma boa oportunidade para produzirem para esse nicho de mercado e assim, aumentarem as vendas, as quais muitos deles relataram que diminuíram muito com a pandemia COVID-19, chegando a $70 \%$.

Entretanto, no contexto geral, a relação com a segurança alimentar e nutricional do município é muito forte, além de atenderem os consumidores com a venda na feira, eles atendem restaurantes e refeitórios de empresas, vendem porta a porta, entregam para o Programa do Leite da Criança (PLC) entre outros, grande parte dos agricultores da feira também vendem para os mercados institucionais Programa Aquisição de Alimentos (PAA) e Programa Nacional de Alimentação Escolar (PNAE), 
dos 39 questionados, $17(43,6 \%)$ e 8 (20,5\%) agricultores familiares vendem para esses mercados, respectivamente, totalizando 25 agricultores $(64,1 \%)$, apresentando a importância do incentivo deste setor para a segurança alimentar e nutricional do município.

Com essas informações se torna possível tomar decisões e desenvolver políticas e estratégias mais assertivas e condizentes com a realidade e com as dificuldades citadas pelos agricultores familiares da feira municipal, possibilitando ainda, atender às oportunidades vislumbradas, como a divulgação por meios digitais. É evidente que a pandemia da COVID-19 desnudou nossas fragilidades e vulnerabilidades e ocasionará mais efeitos negativos do que positivos, no entanto, é uma séria oportunidade de reflexão sobre como produzimos, processamos e distribuímos os alimentos e estando no século XXI temos tecnologia e conhecimento suficientes para que ninguém passe fome ou viva em insegurança alimentar (Schneider et al., 2016), neste viés, é importante que parcerias sejam firmadas e oportunidades sejam vislumbradas para que os efeitos negativos da pandemia sejam amenizados em relação aos agricultores familiares da feira municipal de Cascavel - PR.

\section{Considerações Finais}

Com base no objetivo proposto de compreender e analisar as dificuldades dos agricultores familiares participantes da feira municipal de Cascavel - PR para venderem seus produtos na pandemia COVID-19, foi possível constatar que a pandemia COVID-19 repercutirá de várias formas na agricultura familiar, abrangendo todas as etapas do processo de produção até a oferta de alimentos, exigindo um maior envolvimento entre a gestão da feira municipal e os órgãos municipais, a fim de todos obterem benefícios, pois esse distanciamento foi observado como um limitador para obtê-los.

Os agricultores familiares da feira municipal, relataram dentre outras dificuldades enfrentadas neste momento de pandemia, que tiveram suas vendas diminuídas em até $70 \%$, os clientes ainda têm medo e não se adaptaram a dinâmica da feira na pandemia, ainda houve a mudança de local da feira para um local mais afastado do centro da cidade com poucas vagas de estacionamento para os clientes, esses fatores somados à crise financeira da população, revelam que são necessárias estratégias locais para amenizarem os seus efeitos negativos. Neste viés a gestão da feira está procurando parcerias com universidades, mas também é imprescindível um maior apoio da gestão municipal, frente a importância da agricultura familiar e aos benefícios das feiras para os municípios, gerando renda e fomentando o desenvolvimento local.

Neste sentido, acredita-se que a investigação das dificuldades enfrentadas pelos agricultores da feira municipal de Cascavel - PR possibilita que estratégias sejam formuladas pela gestão da feira e pela gestão municipal, a fim de fomentar as vendas e assim, consequentemente, contribuirá com o fortalecimento e desenvolvimento da agricultura familiar na pandemia e no pós-pandemia, bem como para reduzir os índices de insegurança alimentar e nutricional do município e ainda avivará o desenvolvimento local.

Como sugestões para futuras pesquisas, percebe-se a necessidade da elaboração de estratégias para amenizarem as dificuldades encontradas neste estudo e fomentar as oportunidades vislumbradas, como por exemplo, adoção de tecnologia como o mercado digital para proporcionar maior visibilidade dos produtos vendidos na feira.

\section{Referências}

Almeida, L. M. M. C. et al. (2007). Public policies and food security and family farming networks: contributions to the construction of effectiveness indicators. http://socialsciences.scielo.org/pdf/s_esaa/v3nse/scs_a01.pdf>.

Altafin, I. G. (2003). Sustentabilidade, políticas públicas e agricultura familiar: uma apreciação sobre a trajetória brasileira. 225 f. Tese (Doutorado) Centro de Desenvolvimento Sustentável, Universidade de Brasília, Brasília, DF.

Basso, D., Silva, N. L. S. \& David, A. (2019). Estratégias dos agricultores familiares modernos com racionalidade em transição que vivenciaram o programa de extensão rural da Cresol Baser. Revista Orbis Latina. 9 (1), 231-248. https://revistas.unila.edu.br/index.php/orbis. 
Buainain, A. M. \& Batalha, M. O. (2007). Cadeia produtiva de produtos orgânicos. (5a ed). Bib. Orton IICA/CATIE.

Barron, T. (2021). Entrevista concedida a Elaine Zanini.

Contraf Brasil - Confederação Nacional dos Trabalhadores e Trabalhadoras na Agricultura Familiar. (2020). A importância da agricultura familiar, enquanto produtora de alimentos e o reconhecimento formal da categoria no mundo do trabalho. https://contrafbrasil.org.br/noticias/a-importancia-da-agriculturafamiliar-enquanto-produtora-de-alimentos-e-o-reconh-a302/.

Crespo, T. (2007). Respuestas a 16 preguntas sobre el empleo de expertos em la investigación pedagógica. San Marcos.

Embrapa - Empresa Brasileira de Pesquisa Agropecuária. (2020). Pesquisa mostra o retrato da agricultura digital brasileira. <https://www.embrapa.br/buscade-noticias/-/noticia/54770717/pesquisa-mostra-o-retrato-da-agricultura-digital-brasileira.

Esquerdo-Souza, V. F. \& Bergamasco, S. M. P. P. (2019). Políticas públicas para a agricultura familiar brasileira: um estudo sobre o PRONAF nos municípios do circuito das frutas - SP. Revista Extensão Rural, Santa Maria, RS, 22 (1), 09-35.

Fao - Organização das Nações Unidas para a Alimentação e a Agricultura. (2020). Novo relatório das Nações Unidas revela a desigualdade na distribuição geográfica da má nutrição na América Latina e no Caribe. http://www.fao.org/americas/noticias/ver/es/c/1334327/.

Fao - Organização das Nações Unidas para Alimentação e Agricultura. (2015). Por que a agricultura familiar é importante? http://www.fao.org/familyfarming-2014/pt/.

Freitas et al. (2020). O Impacto da Pandemia sobre as Feiras Livres: Caso Corumbá-MS. Revista Espaço e Tempo Midiáticos. Universidade Federal do Tocantins (UFT), 3 (2), 23-34. https://sistemas.uft.edu.br/periodicos/index.php/midiaticos/article/view/10879.

Gil, A. C. (2010). Como elaborar projetos de pesquisa. (5a ed). Atlas.

Guanziroli, C. E. \& Cardim., S. E. C. S. (2000). Novo retrato da agricultura familiar: o Brasil redescoberto. Brasília: Ministério do Desenvolvimento Agrário, INCRA, Instituto Nacional de Colonização e Reforma Agrária.

Guilhoto, J. J. et al. (2005). Agricultura familiar na economia: Brasil e Rio Grande do Sul. Estudos NEAD 9. MDA.

Leite, D. C. \& Teles, E. C. P. V. A. (2000). Comercialização de produtos agroecológicos a partir de circuitos curtos: a experiência das feiras agroecológicas de Recife, Pernambuco. EXTRAMUROS - Revista de Extensão da UNIVASF, 7 (2), 026-044.

Maluf. R. S. (2004). Mercados agroalimentares e a agricultura familiar no Brasil: agregação de valor, cadeias integradas e circuitos regionais. Ensaios FEE, Porto Alegre, 25 (1), 299-322.

Maluf, R. S. (2000). Atribuindo sentido(s) à noção de desenvolvimento. Estudos Sociedade $e$ Agricultura. 8 (2), 53-86. https://www.revistaesa.com/ojs/index.php/esa/article/view/177/173.

Marca. R. (2020). Entrevista concedida a Elaine Zanini.

Marconi, M. A. \& Lakatos, E. M. (2004). Metodologia Científica. (4a ed.) Atlas.

Malhotra, N. (2001). Pesquisa de marketing. (3a ed). Bookman.

Mda - Ministério do Desenvolvimento Agrário. (2006). Agricultura familiar no Brasil e o censo agropecuário 2006. https://wp.ufpel.edu.br/consagro/files/2010/09/Censo-Agropecu\%C3\%A1rio-e-a-Agricultura-Familiar-2006.pdf.

Mds - Ministério do Desenvolvimento Social e Combate à Fome. (2018). Principais canais de comercialização para a agricultura familiar <http://www.mds.gov.br/webarquivos/arquivo/seguranca_alimentar/compra_institucional/cartilha\%20Principais\%20Caniais\%20de\%20comercializa\%C3\%A7 $\%$ C $3 \%$ A30\%20para\%20Agricultura\%20Familiar.pdf.

Meliczek, H. (2003). A política da FAO para a promoção da agricultura familiar. Redes, Santa Cruz do Sul, 8 (2), $45-66$.

Ops - Organización Panamericana de la Salud. (2020). Panorama de la seguridad alimentaria y nutricional en América Latina y el Caribe. http://www.fao.org/documents/card/en/c/cb2242es.

Paula, N, M. (2017). Evolução do sistema agroalimentar mundial: Contradições e desafios. CRV, 226 p.

Plansan. (2017). Plano Nacional de Segurança Alimentar e Nutricional: PLANSAN 2016 - 2019.

Plansan (2011). Plano Nacional de Segurança Alimentar e Nutricional 2012 -2015.

Plein, C.\& Filippi, E. E. (2011). Capitalismo, agricultura familiar e mercados. Revista Desenvolvimento Regional, 16 (3), 98-121.

Ploeg, J. D. (2011). Trajetórias do desenvolvimento rural: pesquisa comparativa internacional. Sociologias. Porto Alegre, 13 (27), 114-140. https://www.scielo.br/j/soc/a/bCQFRvtWrjHyp5GpMQYvNrH/?lang=pt.

Portal Brasil. (2014). Agricultura familiar encerra 2013 com recordes e traça metas. http://www.brasil.gov.br/economia-e-emprego/2014/01/agriculturafamiliar-encerra-2013-com-recordes-e-traca-metas.

Reis, E., O. (2018). A agregação de valor na agricultura familiar como estratégia para o desenvolvimento local endógeno: o caso das agroindústrias de Panambi-RS. https://repositorio.ufsm.br/bitstream/handle/1/15156/DIS_PPGAGRONEGOCIOS_2018_REIS_ELIANE.pdf?sequence=1\&isAllowed=y. 
Research, Society and Development, v. 10, n. 9, e29310918074, 2021

(CC BY 4.0) | ISSN 2525-3409 | DOI: http://dx.doi.org/10.33448/rsd-v10i9.18074

Scarabelot, M. \& Schneider, S (2012). As cadeias agroalimentares curtas e desenvolvimento local - um estudo de caso no município de Nova Veneza/SC. Faz Ciência, 14 (19), 101-30.

Schneider, S. et al. (2016). Construção de mercados e agricultura familiar: desafios para o desenvolvimento rural. Editora da UFRGS.

Schneider, S. (2009). A pluriatividade na agricultura familiar. (2a ed). Editora da UFRGS.

Sebrae - Serviço Brasileiro de Apoio às Micro e Pequenas Empresas. (2012). Agregar valor aos produtos é um caminho para o aumento da renda do produtor rural. https://sebrae.ms/empreendedorismo/casos-de-sucesso/agregar-valor-aos-produtos-e-um-caminho-para-o-aumento-da-renda-do-produtor-rural/\#.

Senar. (2020). Feiras livres: Produtores apontam queda nas vendas por causa da pandemia do coronavírus. https://www.cnabrasil.org.br/noticias/feiraslivres-produtores-apontam-queda-nas-vendas-por-causa-da-pandemia-do-coronavirus.

Silva, K. M. (2021). Entrevista concedida a Elaine Zanini.

Stofell. J. A. (2004). A viabilidade da agricultura familiar: Formas de organização produtiva no Oeste do Paraná. 128f. Programa de Pós-Graduação em Desenvolvimento Regional e Agronegócio-Mestrado e Doutorado. Toledo. Dissertação (Mestrado em Desenvolvimento Regional e Agronegócio) - PGDRA UNIOESTE.

Tonin. M. (2020). Entrevista concedida a Elaine Zanini. 